\title{
Geographical Distribution of Sugarcane Longhorn Stem Borer, Dorysthenes Buqueti Guerin (Coleoptera: Cerambycidae) and Virulence Bioassay of Metarhizium Anisopliae (Metchnikoff) Sorokin Isolates
}

\author{
Nichanun Kernasa ${ }^{1 *}$, Sopon Uraichuen ${ }^{1,2}$ and Naoto Kamata ${ }^{1,3}$ \\ ${ }^{1}$ Department of Entomology, Kasetsart University, Thailand \\ ${ }^{2}$ National Biological Control Research Center, Kasetsart University, Thailand \\ ${ }^{3}$ Graduate School of Agricultural and Life Sciences, The University of Tokyo, Japan
}

Submission: August 02, 2018; Published: August 21, 2018

*Corresponding author: Nichanun Kernasa, Department of Entomology, Faculty of Agriculture at Kamphaeng Saen, Kasetsart University, Kamphaeng Saen Campus, Nakhon Pathom, 73140, Thailand; Email: agropk@ku.ac.th

\begin{abstract}
Dorysthenes buqueti Guerin (Coleoptera: Cerambycidae) is an economically important pest of sugarcane in Thailand, which causes great reduction in sugarcane yields. Survey of the of its geographical distribution during 2014 to 2015 revealed that $D$. buqueti was found in Central, East, Lower North and Northeastern regions of Thailand. The percentage of infestation by D. buqueti larvae varied from 0 to $57.6 \%$. Factors influencing infestation intensity were determined by considering spatial autocorrelation. Akaike's Information Criteria (AIC) were compared by changing cluster size of survey plots, which was included as a random effect in GLMM using a logistic regression. One-km spatial autocorrelation was found, which are likely to be related to dispersals ability of $D$. buqueti adults. The results of the GLMM also indicated that $D$. buqueti was less abundant in heavy clay soil type whilst it commonly found in clay loam with heavy infestation. The percentage of Sugarcane area (SPC) inside a circle with a 10-km radius showed the smallest AIC, with a significantly negative coefficient of the SPC, indicating that the infestation decreased with a percentage of sugarcane area within the circle with $10-\mathrm{km}$ radius. It suggests a possibility that $D$. buqueti is regulated by specific natural enemies to D. buqueti that can disperse as far as $10 \mathrm{~km}$. The Green Muscadine Fungus (GMF), Metarhizium anisopliae (Metchnikoff) Sorokin has been reported that GMF infects and kills the Sugarcane Longhorn Stem Borer (SLSB), Dorysthenes buqueti Guerin so that the GMF is a possible biological control agent of SLSB. This study revealed that an isolate from Khon Kaen (KK) showed the highest virulence to instars $5^{\text {th }} 9^{\text {th }}$ of SLSB. In biological control, aqueous suspension containing $10^{8}$ conidia/ml of $\mathrm{KK}$ isolate is best from a viewpoint of an economical cost/benefit trade-offs between mass production cost and consequent mortality after application.
\end{abstract}

Keywords: Spatial autocorrelation; \% Sugarcane area; Generalized linear mixed model; Geological information system; Biological control; Conidial suspension; Plant; Rhizosphere stage; Environment; Hymenoptera; lepidoptera; M. Anisopliae species; Sugarcane; Production; Callosobruchus maculatus; Infestation; Fungus; Information criterion

Abbreviations: AIC: Akaike's Information Criteria; GMF: Green Muscadine Fungus; SLSB: Sugarcane Longhorn Stem Borer; KK: Khon Kaen; NBCRC: National Biological Control Research Center; AIC: Akaike Information Criterion

\section{Introduction}

Sugarcane stem boring grub; Dorysthenes buqueti Guerin (Coleoptera: Cerambycidae) recently become a serious insect pest of sugarcane. The severe injury by $D$. buqueti has been extended to sugarcane growing areas i.e.; East and Northeastern region of Thailand -. It can cause more than $70 \%$ yield loss in the outbreak areas. This insect pest attack sugarcane plant by the larval instar bores into the ratoon or the base of stalk and feed sugarcane tissue inside; which results the whole plant turned brown and die. Moreover; it can attack cassava stem and tuber that found in Kanchanaburi province. The concern of extensive insecticide application has been enforced explorations of natural enemies to control D. buqueti. Metarhizium anisopliae (Metchnikoff) Sorokin is a soil borne entomopathogenic fungus had been reported to exploiting to control D. buqueti in sugarcane fields. Metarhizium spp. are always designated as soil saprophytes that were observed in associations with plant roots in the rhizosphere stage and survive well in that environment over the longtime [1]. The Green 
Muscadine Fungus (GMF); Metarhizium anisopliae (Metchnikoff) Sorokin; is an entomopathogenic fungus that is worldwide in distribution from the arctic to the tropics. The fungus was recorded from both agricultural and forest soils. Approximately 200 species of insects including the order Symphyla; Orthoptera; Dermaptera; Isoptera; Homoptera; Heteroptera; Diptera; Hymenoptera; Siphonoptera and Lepidoptera and other arthropods were known as hosts of GMF [2]. However; it was also reported that each isolate of GMF is found specific to insect species as its host [3]. In this manuscript; we use the term "GMF" for M. anisopliae species complex.

Various strains of the GMF were also recorded in Thailand. The objectives of the present study were survey of geographical distribution $D$. buqueti in industrial sugarcane plantations in Thailand and re-examined virulence of GMF isolates collected from $D$. buqeuti cadavers found from sugarcane plantations in Thailand by bioassays to $D$. buqueti larvae.

\section{Materials and Methods}

\section{Study on geographical distribution of $\mathrm{D}$. buqueti}

216 survey points were arbitrarily selected from sugarcane plantations within $50 \mathrm{~km}$ radius from a sugar mill. The GPS map 60CSx (Garmin; USA) was used for recording latitude; longitude and elevation data of the survey points. These survey points were put on the sugarcane plantation map: data source from the Office of The Cane and Sugar Board.

\section{Study on factors influencing D. buqueti distribution and infestation}

30 stumps were arbitrarily selected at each survey point. Numbers of infested/uninfested stalks in each stump were recorded. The model selection to determine the effects of soil types were calculated by GLMM. Soil type of each survey point was obtained from LDD and Sugarcane plantation map: data source from the Office of The Cane and Sugar Board.

\section{Virulence bioassays}

The bioassay was carried out at the National Biological Control Research Center (NBCRC); Central Regional Center (CRC); Kasetsart University; Kamphaeng Saen Campus; Nakhon Pathom. The larvae of SLSB that were collected from sugarcane fields in Lao Khwan district; Kanchanaburi and Kamphaeng Saen district; Nakhon Pathom were reared individually in plastic cups with artificial diet for the sugarcane borer; Diatraea saccharalis; (Southland Product Inc; AR; USA) for 30 days to ensure they have not been parasitized by any parasitoids. The healthy larvae were used for the virulence bioassays. The $5^{\text {th }}$ to $9^{\text {th }}$ in stars of SLSB were evaluated against four fungal isolates (KK; LKKB; BBCB and DMTK) among the six. Fifty microliters of a conidial suspension of three concentration levels; $10^{3} ; 10^{3}$ and $10^{13}$ conidia/ml (conidia mixed with sterile distilled $\mathrm{H} 2080 \mathrm{ml}$ and Triton X 0.05\%) were dropped on larvae cuticle. Larvae that were treated by $50 \mu \mathrm{l}$ of distilled water mixed with Triton X $0.05 \%$ were equally used as control.
The larvae were discretely placed in plastic box; $23 \mathrm{~cm}$ diameter by $8.5 \mathrm{~cm}$ height; with five pieces of sugarcane stalks; $5 \mathrm{~cm}$ long as food. The sugarcane stalks were replaced to new ones every two weeks. Five replications were conducted with five larvae per replication for each isolate. The treated SLSB larvae were incubated at $25 \pm 2{ }^{\circ} \mathrm{C} ; 43 \pm 2 \% \mathrm{RH}$ and checked daily by naked eyes for mortality if white conidia appear on the cuticle of the larvae. The effects of collection site (KK; LKKB; BBCB; and DMTKB); instar $\left(5^{\text {th }}-9^{\text {th }}\right)$; and concentration of conidial suspension $\left(10^{3} ; 10^{5}\right.$; and $\left.10^{13}\right)$ on the larval mortality were evaluated using a Generalized Linear Model (GLM); with a binomial error structure and a logit link function (a logistic regression). Regarding the three explanatory variables; the "Collection site" was categorical with KK isolate as a base model. The "instar $(5 ; 6 ; 9)$ " and the "concentration $(3 ; 8 ; 13)$ " were numeric. A response variable was a grouped data of numbers of dead and alive insects in each plastic box that contained five individuals of SLSB. To determine if an effect of each variable was significant; Akaike Information Criterion (AIC) was compared between the full model and a model that contained two explanatory variables out of the three.

\section{Results and Discussion}

\section{Study on geographical distribution of $D$. buqueti}

Survey of the of its geographical distribution during 2014 to 2015 revealed that $D$. buqueti was found in Central; East; Lower North and Northeastern regions of Thailand (Figure 1).

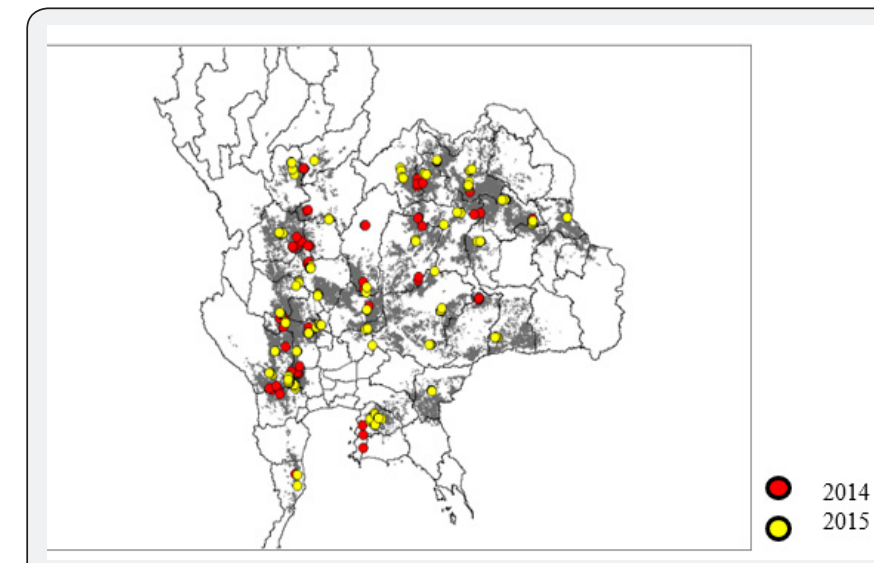

Figure 1: Geographical distribution of $D$. buqueti in sugarcane plantations in Thailamd during 2014-2015

\section{Study on factors influencing $D$. buqueti distribution and infestation}

Heavy clay depressed the damage on sugarcane stalks by $D$. buqueti (Table 1). The percentage of infestation by $D$. buqueti larvae varied from 0 to $57.6 \%$. The damage tended to be severe in 2014 than 2015. Two different scales of mechanisms acted to \%damage by $D$. buqueti via land use found that a positive effect (increase in damage with \%sugarcane fields) at a small scale with $0.5 \mathrm{~km}$; and a negative effect (decrease in damage with $\%$ sugarcane fields) at a larger scale with $20 \mathrm{~km}$. (Table 2). 


\section{Advances in Biotechnology \& Microbiology}

Table 1: Model selection for GLMM to determine effects of soils.

\begin{tabular}{|c|c|c|c|c|c|c|c|c|c|}
\hline \multirow[t]{2}{*}{ Factor } & \multicolumn{2}{|c|}{ Full Model } & & \multicolumn{2}{|c|}{ Best Model } & & \multicolumn{2}{|c|}{ Second Model } & \\
\hline & Coefficient & p-value & & Coefficient & p-value & & Coefficient & p-value & \\
\hline (Intercept) & 1.817737 & 0.0573 & . & 1.800329 & 0.0572 & . & 2.472944 & 0.00423 & $* *$ \\
\hline Clayy & -0.72227 & 0.2323 & & -0.96688 & 0.0556 & & -1.17842 & 0.01628 & $*$ \\
\hline Heavy Clayy & -2.06289 & 0.0356 & $*$ & -1.97166 & 0.0465 & $*$ & -1.95256 & 0.05113 & \\
\hline Coars eloamy & 0.570178 & 0.2995 & & & & & & & \\
\hline Loamy & 0.885271 & 0.0939 & . & 0.595148 & 0.1265 & & & & \\
\hline Sandy & 0.170754 & 0.7538 & & & & & & & \\
\hline Loamy sandy & 1.046148 & 0.2277 & & & & & & & \\
\hline Sandy Loamy & -0.79239 & 0.2542 & & & & & & & \\
\hline Year 15 & -3.40193 & $1.31 \mathrm{E}-14$ & $* * *$ & -3.37008 & $<2 \mathrm{e}-16$ & $* * *$ & -3.27061 & $<2 \mathrm{e}-16$ & $* * *$ \\
\hline $\mathrm{X}$ & -0.0058 & $3.18 \mathrm{E}-06$ & $* * *$ & -0.00549 & $5.78 \mathrm{E}-06$ & $* * *$ & -0.00627 & $2.92 \mathrm{E}-08$ & $* * *$ \\
\hline Aic & 7478.3 & & & 7475.2 & & & 7475.5 & & \\
\hline
\end{tabular}

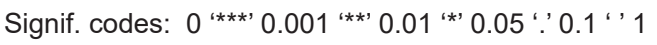

Table 2: Effect of land use calculated by logistic regression.

\begin{tabular}{|c|c|c|c|c|c|c|c|c|c|c|}
\hline & NO SPC & $\mathbf{0 . 5}$ & $\mathbf{1}$ & $\mathbf{2}$ & $\mathbf{5}$ & $\mathbf{1 0}$ & $\mathbf{2 0}$ & $\mathbf{5 0}$ & $\mathbf{1 0 0}$ \\
\hline AIC & 9679.1 & 966.3 & 9678.7 & 9675.1 & 9644.8 & 9618.3 & 9595.7 & 9626.7 & 9680.8 \\
\hline \multicolumn{7}{|c|}{ Estimate } \\
\hline (Intercept) & -0.68685 & -0.97539 & -0.80165 & -0.48107 & -0.1666 & 0.040569 & 0.176598 & 0.061685 & -0.64214 \\
\hline Heavyclayy & -1.38409 & -1.36207 & -1.36786 & -1.42247 & -1.4617 & -1.50489 & -1.52364 & -1.31613 & -1.36625 \\
\hline Year 15 & -1.26464 & -1.21346 & -1.23942 & -1.30815 & -1.37104 & -1.39002 & -1.39366 & -1.25738 & -1.26221 \\
\hline X & -0.00199 & -0.0018 & -0.00192 & -0.00215 & -0.00239 & -0.00256 & -0.00262 & -0.00257 & -0.00202 \\
\hline Spc & & 0.004195 & 0.001799 & -0.00323 & -0.00932 & -0.01537 & -0.02292 & -0.03631 & -0.00459 \\
\hline \multicolumn{7}{|c|}{$\mathbf{p}-$ palue } & & & \\
\hline (Intercept) & $-1.10 \mathrm{E}-08$ & $-1.80 \mathrm{E}-12$ & $-1.20 \mathrm{E}-08$ & -0.00105 & & & & $-6.60 \mathrm{E}-06$ \\
\hline Heavyclayy & $-2.00 \mathrm{E}-16$ & $-2.00 \mathrm{E}-16$ & $-2.00 \mathrm{E}-16$ & $-2.00 \mathrm{E}-16$ & $-2.00 \mathrm{E}-16$ & $-2.00 \mathrm{E}-16$ & $-2.00 \mathrm{E}-16$ & $-2.50 \mathrm{E}-16$ & $-2.00 \mathrm{E}-16$ \\
\hline Year 15 & $-2.00 \mathrm{E}-16$ & $-2.00 \mathrm{E}-16$ & $-2.00 \mathrm{E}-16$ & $-2.00 \mathrm{E}-16$ & $-2.00 \mathrm{E}-16$ & $-2.00 \mathrm{E}-16$ & $-2.00 \mathrm{E}-16$ & $-2.00 \mathrm{E}-16$ & $-2.00 \mathrm{E}-16$ \\
\hline X & $-2.00 \mathrm{E}-16$ & $-2.00 \mathrm{E}-16$ & $-2.00 \mathrm{E}-16$ & $-2.00 \mathrm{E}-16$ & $-2.00 \mathrm{E}-16$ & $-2.00 \mathrm{E}-16$ & $-2.00 \mathrm{E}-16$ & $-2.00 \mathrm{E}-16$ & $-2.00 \mathrm{E}-16$ \\
\hline Spc & & $2.01 \mathrm{E}-05$ & & -0.01457 & $-2.40 \mathrm{E}-09$ & $-3.70 \mathrm{E}-15$ & $-2.00 \mathrm{E}-16$ & $-2.10 \mathrm{E}-13$ & \\
\hline
\end{tabular}

\section{Virulence bioassays}

By inoculation experiment; mortality tended to increase with concentration of conidial suspension (Figure 2). No mortality was observed in the control (data were not shown in the graph) and at $10^{3}$ conidia/ml. A delta AIC between the full model and a model with two explanatory variables among the three was greater than 2.57 for all the three explanatory variables indicating that effects of the three factors were all significant ( $p<0.01$ ) (Table 3). In a result of the full model; a coefficient of concentration was positive and significantly differed from zero $(\mathrm{p}<0.01)$ supporting the tendency that the mortality increased with concentration in Figure 1. A coefficient of instar was negative and significantly differed from zero $(p<0.01)$ indicating that the mortality decreased with instar. Actually; in Figure 1; mortality of $9^{\text {th }}$ instar was smaller than the other instars at concentrations of $10^{8}$ and $10^{13}$ conidia/ $\mathrm{ml}$. The result also indicated that effects of $\mathrm{KK}$ isolate was larger than the other three isolates because all the coefficients of other three isolates were negative. The difference was significant for
LKKB isolate $(\mathrm{p}<0.01)$ and for DMTKB isolate $(\mathrm{p}<0.05)$ but marginally significant for $\mathrm{BBCB}(\mathrm{p}=0.09)$. Regarding the $\mathrm{KK}$ isolate; a slope between $10^{3}$ and $10^{8}$ conidia/ml was steeper than that between $10^{8}$ and $10^{13}$ conidia/ml (Figure 1) suggesting that suspension containing $10^{8}$ conidia/ml of $\mathrm{KK}$ isolates is best from a viewpoint of an economical cost/benefit trade-offs between mass production cost and consequent mortality after application. Namely; comparing suspensions containing $10^{8}$ conidia/ml with those containing $10^{13}$ conidia/ml; $100 ; 000$ times as much quantity of suspension will be obtained from the same quantity of conidia though the difference in the $D$. buqueti mortality was relatively small. Many studies reported that aqueous GMF suspensions of $10^{8}-10^{9}$ conidia/ml were effective to kill many species of insects. Sommartya, et al. [4] found that the mortality of larvae was $100 \%$ at 14 days after inoculation with a conidial suspension of $1 \times 10^{8}$ conidia/ml in the greenhouse. Marannini, et al. [5] revealed that M. anisopliae of aqueous suspension containing $10^{8}$ conidia/ $\mathrm{ml}$ showed pathogenicity for neonate larvae of $C$. tenebrionis with a variation in mortality from 23.5 to $100 \%$. A similar result 
was shown by Cherry, et al. [2]; which revealed that aqueous suspension containing $10^{8}$ conidia/ml showed high virulence to Callosobruchus maculatus in stored cowpea. Mishra, et al. [6] also reported that suspension containing $4.1 \times 10^{8}$ conidia/ml acted as an effective larvicide to Musca domestica. Benserradj and Mihoubi
[1] reported that suspension containing $10^{9}$ conidia/ml showed the highest mortality to the 4th instar of Culex pipiens. These supports that our conclusion that GMF containing $10^{8}$ conidia $/ \mathrm{ml}$ was likely the most suitable concentration to control $D$. buqueti larvae from a viewpoint of an economical cost-benefit trade-offs.

\section{KK}

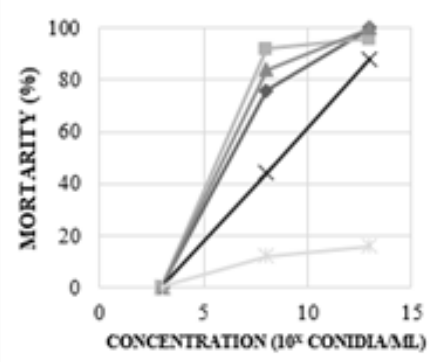

\section{LKKB}

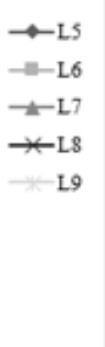

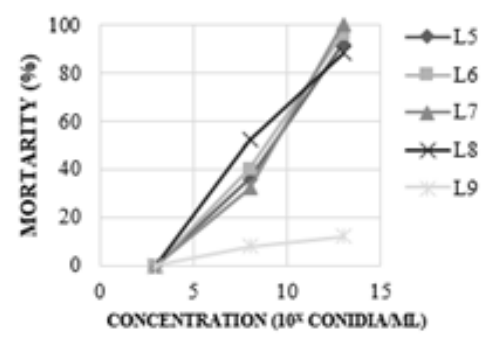

(D)

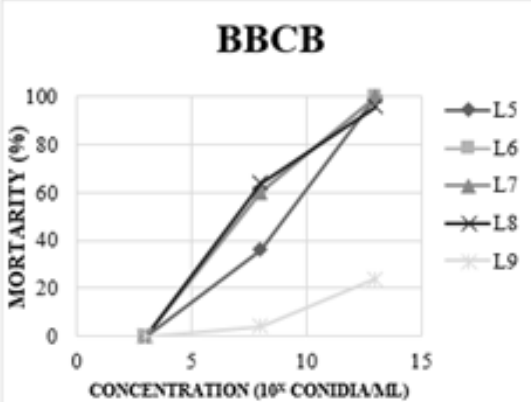

(C)

DMTKB

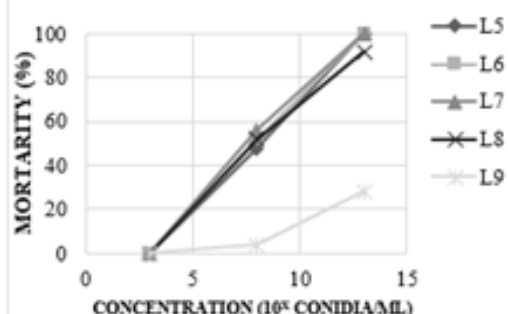

Figure 2: The percentage mortality of $D$. buqueti larvae by conidial suspension of four green muscadine fungus isolates. Instars: $5^{\text {th }}-9^{\text {th }}$ Conidial concentrations: 103, 108 and 1013 conidia/ml. No mortality was found in a control

Table 3: Results of Generalized Linear Model (GLM) evaluating effects of Green Muscadine Fungus (GMF) isolates, concentration of the conidial suspension, and Dorysthenes buqueti instar on mortality by the fungus with a binominal error structure and a logit link function. The KK isolate was used for a base model.

\begin{tabular}{|c|c|c|c|c|}
\hline Model & AIC & ?AIC & & \\
\hline Full model & 666.5 & & & \\
\hline - Isolate & 677.5 & 11 & & \\
\hline - Instar & 844.7 & 178.2 & & \\
\hline -Concentration & 1557 & 890.5 & & p-value \\
\hline Estimate & SE & zalue & 0.2893 \\
\hline Intercept & 0.44292 & 0.41803 & 1.06 & 0.0907. \\
\hline Isolate (BBCB) & -0.37403 & 0.22111 & -1.692 & $0.0436^{*}$ \\
\hline $\begin{array}{c}\text { Isolate } \\
\text { (DMTKB) }\end{array}$ & -0.44678 & 0.22139 & -2.018 & $5.06 \mathrm{e}-05$ \\
\hline Isolate (LKKB) & -0.90906 & 0.22429 & -4.053 & $* * *$ \\
\hline Instar & -0.76833 & 0.06453 & -11.91 & $<2 \mathrm{e}-16^{* * *}$ \\
\hline Concentration & 0.5834 & 0.02879 & 20.267 & $<2 \mathrm{e}-16^{* * *}$ \\
\hline
\end{tabular}

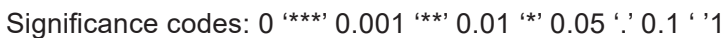

\section{Conclusion}

Heavy clay depressed the damage on sugarcane stalks by $D$. buqueti. \%damage by $D$. buqueti via land use found that a positive effect (increase in damage with \%sugarcane fields) at a small scale with $0.5 \mathrm{~km}$; and a negative effect (decrease in damage with \%sugarcane fields) at a larger scale with $20 \mathrm{~km}$. A positive effect at a small scale is likely to relate to movement of $D$. buqueti. A negative effect at a larger scale is possibly to be related to distribution or movement of natural enemies This study revealed that KK isolate which was collected from Khon Kaen showed the highest virulence to L5 - L9 of D. buqueti. In biological control; aqueous suspension containing $10^{8}$ conidia/ml of $\mathrm{KK}$ isolates is best from a viewpoint of an economical cost/benefit trade-offs between mass production cost and consequent mortality after application.

\section{References}

1. Benserradj O, Mihoubi (2014) Larvicidal activity of entomopathogenic fungus Metarhizium anisopliae against mosquito larvae in Algeia. Int J Curr Microbiol App Sci 3(1): 54-62.

2. Cherry AJ, Abalo P, Hell K (2005) A laboratory assessment of the potential of different strains of the entomopathogenic fungi 
Beauveria bassiana (Balsamo) Vullemin and Metarhizium anisopliae (Metschnihoff) to control Callosobruchus maculatus (F.) (Coleoptera Bruchidae) in stored cowpea. J Stored Prod Res 41(3): 295-309.

3. Zimmermann G (2007) Review on safety of the entomopathogenic fungus Metarhizium anisopliae. Biocontrol Sci Tech 17(9): 879-920.

4. Sommartya P, W Suasa-ard, A Puntongcum (2007) Natural enemies of sugarcane longhorn stem borer, Dorysthenes buqueti Guerin Coleoptera: Cerambycidae), in Thailand, pp. 858-862. In XXVI Congress, International Society of Sugar Cane Technologists, ICC. Durban, South Africa.
5. Marannini P, C Santiago-Álvarez, E de Lillo, E Quesada-Morago (2006) A new bioassay method reveals pathogenicity of Metarhizium anisopliae and Beauveria bassiana against early stages of Capnodis tenebrionis (Coleoptera: Buprestidae). J Invertebr Pathol 93(3): 210-213.

6. Mishra S, P Kumar, A Malik, S Satya (2011) Adulticidal and larvicidal activity of Beauveria bassiana and Metarhizium anisopliae against housefly, Musca domestica (Diptera: Muscidae), in laboratory and stimulated field bioassays. Parasitol Res 108(6): 1483-1492.

\section{Your next submission with Juniper Publishers will reach you the below assets}

- Quality Editorial service

- Swift Peer Review

- Reprints availability

- E-prints Service

- Manuscript Podcast for convenient understanding

- Global attainment for your research

- Manuscript accessibility in different formats

( Pdf, E-pub, Full Text, Audio)

- Unceasing customer service

Track the below URL for one-step submission https://juniperpublishers.com/online-submission.php 